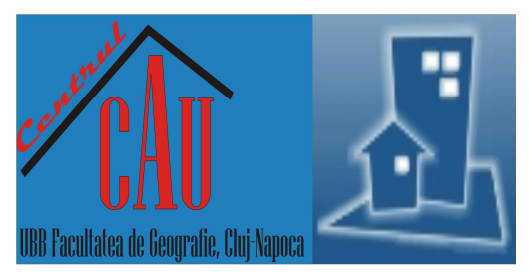

\title{
Using Integrated Spatial Planning Framework "ISPF" to Connect Informal Settlement to the Main City. Case Study: Komb, Chabahar City, Iran
}

\author{
Alireza MOHAMMADI \\ ${ }^{1}$ University of Mohaghegh Ardabili, Faculty of Humanities, Department of Geography and Planning, Ardabil, IRAN \\ E-mail: a.mohammadi@uma.ac.ir \\ DOI: 10.24193/JSSP.2017.2.04 \\ https://doi.org/10.24193/JSSP.2017.2.04
}

K e y w o r d s: in situ upgrading, informal settlement, integrated spatial planning framework, Komb, City of Chabahar

\begin{abstract}
A B S T RA C T
The lack of appropriate spatial planning methods in developing countries such as Iran has led to the isolation and separation of some informal settlements from the main cities. In most cases, an Integrated Spatial Planning Framework has not been provided to integrate informal settlements into the main cities. One of these settlements is called "Komb" which is located in Chabahar in the southeast of Iran. This settlement was separated from the main city and it has grown into a slum. This article aims to use an integrated spatial planning framework to connect and integrate this settlement with the main city. To achieve this goal, "integrated spatial planning framework" approach has been used including four levels as follows: city, neighborhood, neighborhood units, and land pieces. The results indicate that this approach is a suitable and practical model to connect the informal settlement of Komb to the main city of Chabahar.
\end{abstract}

\section{INTRODUCTION}

According to estimates, in 2015, about 863 million people in the world were living in urban slums, and about $90 \%$ of this population in developing countries is living in slums [1]. Moreover, about $43 \%$ of the urban population in Asian countries [2] and about $30 \%$ of the urban population in Iran have been living in slums by 2017 [2], [3], [4]. Since the 1960s onward, there has not been an integrated approach in spatial planning in Iran to deal with this issue; however, different approaches such as demolition and clearance of settlements and eviction of their inhabitants, resettlement, construction of public housing, upgrading and empowerment have been experienced [5]. Most of these methods were not able to be generalized, repeated, and modelled at broader scales. During the recent decades there has been the consensus that in situ upgrading provides a good opportunity for organizing [6]. Despite this consensus, it is not clear yet how to implement the approach and achieve best results in different geographical conditions in cities. Most solutions are divided to two distinct classes, namely physical measures and sector measures, while lacking in integrated planning to upgrade the neighbourhoods. According to Amis (2001), social developments and consequences of upgrading measures are not evaluated at all [7]. Over the past decades, two operational options have been followed and promoted for in situ upgrading of informal settlements. The first option is "Public Principles" which has often been proliferated based on the activities of NGOs and some researchers and practitioners. The second option is "Best Practices" which has been promoted by the United Nations Centre for Human Settlements. However, according to Abbott (2000a) both options, as means of upgrading informal settlements, have failed in terms of approach because of the mere emphasis on physical engineering approach. According to Abbott (2000a; 200ob) upgrading 
solutions are mainly holistic or physical and seldom have an integrated, blended, and long-term look at upgrading informal settlements [8], [9].

Chabahar city, with a population of about 95 thousand people, is one of the cities faced with the problem of marginalization. According to studies, there are 13 informal settlement zones in Chabahar. The entire area of informal settlements in this city covers about 880 hectares (38\% of the city area) and 30,000 people (about $41 \%$ of the city population) are residing in informal settlements. Economic attractions of Chabahar, free trade zone and regional poverty are the major reasons for migration to the city and formation of informal settlements [10]. The problem is that one of the informal neighbourhoods in city, which is called "Komb", has been formed and has grown quickly outside the legal bounds and urban services and became an isolated place from the city. At present, no services are provided for this settlement by the municipality and its inhabitants are living in dreadful conditions. The physical condition of settlement is terrible and growing in the same way. Therefore, it is highly essential to connect this settlement to the main city to upgrade it and to improve its inhabitants' living conditions. This study aims to offer an integrated spatial planning framework to connect the settlement of Komb to the main city. The main question of the research is "How an integrated spatial planning program can be used to connect informal settlement of Komb to the main city?". The article includes an introduction, theoretical framework, methodology and data, results, discussion and conclusion.

\section{THEORETICAL BACKGROUND}

\subsection{Approaches for in situ upgrading of informal settlements}

The common approaches for "in situ upgrading" of informal settlements can be classified into four groups. The first approach is sector intervention. In this approach, basic and fundamental requirements of the inhabitants in informal settlements such as supplying drinking water are recognized. The whole spatial structure of the settlement does not change, however, in this approach. The second approach is physical upgrading. This approach focuses on physical upgrading of the whole settlement by providing comprehensive layout and without caring for essential needs. This approach has often been used in physical organization of informal settlements in South American countries, Africa, and Asia until 2000. According to Abbott (2000a) both approaches failed to elaborate an appropriate methodology [8]. Using the lessons and experiences of Belo Horizonte, Abbott (2000a) has suggested the third approach. In his proposed approach upgrading must be an integration of physical and sector measures. In this approach, informal settlement requirements are upgraded in situ [8]. However, since 2000 onward, the UN-HABITAT has tried to offer an integrated and repeatable approach entitled Citywide Slum Upgrading. This approach tries to organize informal settlements in situ and without extensive physical changes [11], [12]. According to this approach, informal settlement is not seen as a location isolated from conventional city, but a settlement recognized in the urban planning system. Long-term prospects are drawn for settlement upgrading and efforts are made to connect slums to conventional cities and integrated urban planning is made in relation to them. In Citywide upgrading approach, partnership, streets network and spatial dimensions are the three key points. In Citywide upgrading, efforts are made to connect informal settlements to the main cities by taking hyper local measures [2]. In Iran, before 2003, when the national empowerment document was approved, an appropriate, systematic, and repeatable approach for organizing in the original in situ organizing of informal settlements had not been adopted [5].

\subsection{Literature of in situ upgrading of informal settlements}

In situ upgrading of informal settlement is taking measures that lead to changes in life quality of dwellers and improvement of their environmental conditions. There has been a public consensus on this approach since the 1960s. At the beginning of the implementation of this strategy the interventions were physical. Since the 1980 s onward, participatory, economic, and social approaches have been highlighted in terms of empowerment trends [13] which have led to the rise of community-based upgrading pattern. The main assumption in physical upgrading method was that numbness, chaos and pollution would be removed from informal settlements [14]. However, the problem was that with the rapid growth of urbanization in underdeveloped and poor countries, informal settlements mainly affected by economic and social issues, were growing quickly [15]. Therefore, institutions like the World Bank (1991) sought for solutions with more stable and long-term effects and consequences that would consider economic and social aspects of upgrading [16]. According to the World Bank (1991) understanding this matter required playing a practical role in development thinking in which it had stepped [16]. A new mechanism was needed to implement in situ upgrading of informal settlements, which would emphasize on the suppliance of the cost of services [17], [18]; it also meant that objective changes and services provided for the local community were tangible and the use of standards and norms of planning and designing was possible according to this 


\section{Using Integrated Spatial Planning Framework "ISPF" to Connect Informal Settlement to the Main City. Case Study: Komb, Chabahar City, Iran \\ Journal of Settlements and Spatial Planning, vol. 8, no. 2 (2017) 107-117}

approach [13]. According to the results of Cities Alliance (1999) in situ upgrading of informal settlements is an integrated approach to improve economic, social, institutional conditions and activities associated with local community [19]. Satterthwaite (2012) believes that upgrading is promoting the quality of housing, infrastructures, and services in informal settlements [20]. Upgrading concentrates on and cares for promoting basic services, land tenure security and access to finances. Satterthwaite (2012) believes that successful upgrading requires the participation and partnership of state, private and non-governmental institutions and local community [20]. But, Huchzermeyer (1999) believes that local community participation and trust in internal capabilities of local communities are the foundation of upgrading informal settlements [17]. Abbott (2002a), however, believes that this approach alone and at the neighbourhood scale does not guarantee the organization of informal settlement and has some deficits in terms of methodology [13]. Therefore, he suggests the integrated spatial approach and the basic method to ensure the sustainability of the approach. The UN-HABITAT (2014c) also introduces citywide upgrading approach as the foundation for the organization of informal settlements [21].

\subsection{Integrated spatial planning}

Over the past decades, two kinds of experimental and theoretical methods have often been used to organize informal settlements. The experimental method is derived from practices and scientific methods and mainly depends on experience [22], [23]. These methods can become a common framework through recognizing, understanding, and replicating the community-based spatial planning as well as small-scale and executive planning [24]. Theoretical approach is a conceptual framework that delineates the process of events as they occur and thereby provides a theoretical model to be used for upgrading programs and projects. In the case of theoretical approach, theory and practice are interconnected and each one uses the advantages of the other. In the theoretical case there are three subject patterns used to upgrade informal settlements [13]:

infrastructures;

$$
\text { - mproving and promoting physical }
$$

- community action planning;

- physical transformation and changes through comprehensive (integrated) planning.

According to Abbott (2002a; 2002b), due to lack of methodology, none of the three approaches is efficient for spatial planning and organizing informal settlements and this means that new methods need to be offered [6], [13]. Abbott (2000a) introduces basic- procedure approach as the appropriate spatial approach [8] which is named "integrated spatial planning" in this study. Basic-procedure approach seeks to organize informal settlement at different scales and tries to reduce injuries in informal settlements such as the ones resulting from poverty growing [16], environmental and natural disasters such as floods [25], drought [26], high levels of surface water, settlement around mines and industries, proximity to faults and other harmful environmental elements [6]. Moreover, a number of issues can be referred to, as follows: threats to human health such as insecure settlement and threats of eviction from constructed houses and lands [27], mental disorders and risky behaviour [28], contagious diseases [29], robbery, rape, violence and harassment [30], injuries caused by differences in the use of unoccupied spaces and lands, differences in the use of public and private spaces [29] and economic damage [31].

According to Moser (1995a) the highest possible damage affecting the local community of informal settlements is the insecurity and the threat of loss of assets [31]. From the spatial planning perspective, reducing the abovementioned damages is not limited to the realm of informal settlements and the implementation of the UN-HABITAT policy [32], i.e. according to the Recife Declaration, a special link of the "margin" to "the text" or of the informal settlement to the main city is essential. In subsequent steps, all of the elements discussed in relation to vulnerability need to be considered in spatial planning process. Special planning approach does not merely have physical or sector approach. Using the cross-sector planning phrase, Moser (1995b) tries to prove that need-oriented approach and cross-sector approach are critical in spatial planning so as to organize informal settlements [33]. With regard to different features, level of participation as well as differences in issues, demands and needs of local communities, it is necessary to consider different spatial levels in spatial planning to organize informal settlements [6] and these levels constitute the backbone of the spatial planning model. The integration of informal settlements is very efficient in the case of settlements with scattered, irregular pattern without specific spatial divisions and without basic infrastructures and services [6].

As one of the most important messages of the HABITAT III conference which was held in Quito, Ecuador's capital in 2015 with the slogan "New Urban Agenda", was to connect informal settlements to the main cities with integrated spatial planning approach and in situ upgrading, the proposed model in this research has been elaborated by emulating the practical guide to planning Citywide informal settlements, provided by the UN HABITAT [11], [21] and methodbased planning approach offered by John Abbott. 


\subsubsection{Integrated spatial planning levels}

In order to connect informal settlements to the main cities, some 4 main levels can be offered for an integrated spatial planning:

\subsubsection{Integrating informal settlements with surrounding areas}

At this level, the attempt is to create a connection between informal settlements and their surrounding neighbourhoods and areas through spatial planning. The settlement, ultimately, might be managed separately in terms of institutional structure, but it will be interconnected in terms of spatial structure [6]. In other words, the informal settlement is linked to the main city. In this approach, which is derived from Citywide approach, streets and communication network have key roles in upgrading urban slums and can link them to main cities by playing economic, social, and cultural roles [11], [21]. The UN-HABITAT seriously concentrated on communication network in informal settlements particularly in 2014 and introduced it as an important step in organizing slums. In this approach, street-led slum upgrading leads to spatial connection and link as well as integration between settlements and the main cities which results in the promotion of economic and social interactions [11], [34].

\subsubsection{Reforming inter-neighbourhood spatial structure}

Spatial and geographical structures are essential for organizing informal settlements and linking informal settlements with the main cities. Having sufficient information about physical condition of these areas contributes particularly to the adoption of policies, measures, and the organization of planning [21]. At this level, through the participation of municipal and regional institutions, NGOs and CBOs and agents and the steering committee of settlements, they will gradually try to organize laws and regulations related to construction, communication network, land zoning and service distribution in accordance with urban standards. Moreover, they will attempt to prevent environmental injuries and hazards in risk prone areas of settlements through planning [6]. Particularly, street-based upgrading of informal settlements [34] will be emphasized. Passages network-based spatial upgrading provides the context for organizing neighbourhoods [6].

At this level, in terms of spatial planning, roads and communication network within the neighbourhood play a key role. Street-based upgrading leads to drawing the borders of neighbouring units, formation of new employment and public places, further social interactions, and improvement of security and safety. Streets network upgrading contributes to gradual upgrading of settlements, zoning, plotting, and improvement of land ownership. It also contributes to re-distribution of services, spatial justice and fair distribution of job opportunities in informal settlements. Street-based upgrading leads to the promotion and improvement of job status and life quality in local community. Overall, through the improvement of communication network, settlement upgrading changes squatter dwellers into citizens, informal settlement to neighbourhood and shack to appropriate housing [11], [21]. This study mainly focuses on street-based upgrading. 2.3.1.3. Upgrading in small-scale spatial units
(neighbourhood units)

Spatial scale is most often ignored in upgrading, which leads to the failure of upgrading programs. Whenever structural and demographic density is low per area unit and the settlement is formed on a scattered pattern, land readjustment is inevitable. In such cases, the settlement and local community need to be divided into smaller spatial segments. This scale is smaller than the whole settlement and leads to better recognition and analysis of spatial and social issues of the settlement. This approach converts settlements into smaller parts and neighbourhoods, thus trying to identify the issues are meaningful to adjacent neighbours not at the scale of neighbourhood or household (residential unit). Particularly due to the importance of neighbourhood and social relations at this scale, in informal settlements, division provides the context for the participation of local community at smaller scales [6]. Land readjustment is the most important policy that can be used at this scale particularly in the case of informal settlements without formal ownership system and land plotting. Land readjustments not only can organize neighbouring units but they can also improve services through physical changes and subsequently contribute to the increase of household assets [35].

\subsubsection{Scale of land pieces (household unit)}

At this level, the scale and base are land units and households. At this level, households have different needs and priorities, which derive from poverty and marginalization. Lack of security in residence and ownership, addiction, irresponsibility, lack of guardian, illness, violence, etc., are the issues for which is planning possible at the household scale. Studies have shown that most families exposed to social risks and anomalies are deprived from access to appropriate income and job opportunities [36]. According to Ruster and Imperato (2000), mediation between local community and households and upgrading custodians 
is an essential and effective tool in empowering households at this level [37]. Moreover, understanding the needs of families through social work is particularly important and has a profound effect on the success of upgrading plans [6].

The integrated spatial planning framework applied in this study (Fig. 1) attempts to provide the ground for integrating informal settlements with the main cities by proposing spatial measures on four scales. In this study, it has been tried to propose the theoretical framework for Komb settlement according to the available spatial data.

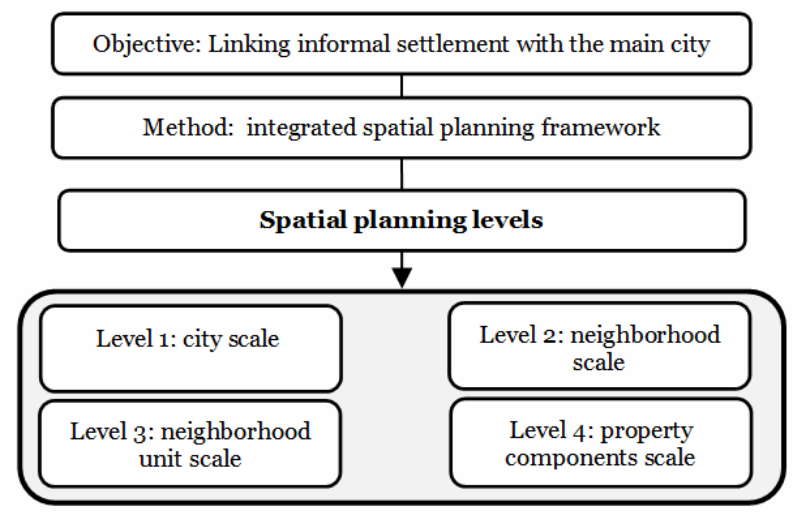

Fig. 1. Conceptual framework of ISPF.

\section{METHODOLOGY}

\subsection{Study area}

Chabahar is located south-east of Iran $\left(69.6431^{\circ} \mathrm{E}\right.$ and $\left.25.2919^{\circ} \mathrm{N}\right)$. The city population is of 95,000 people and its area is of 2,700 hectares. Komb is the name of the informal settlement that is located on the eastern outskirts and outside the area of Chabahar municipal services [10] (Fig. 2).

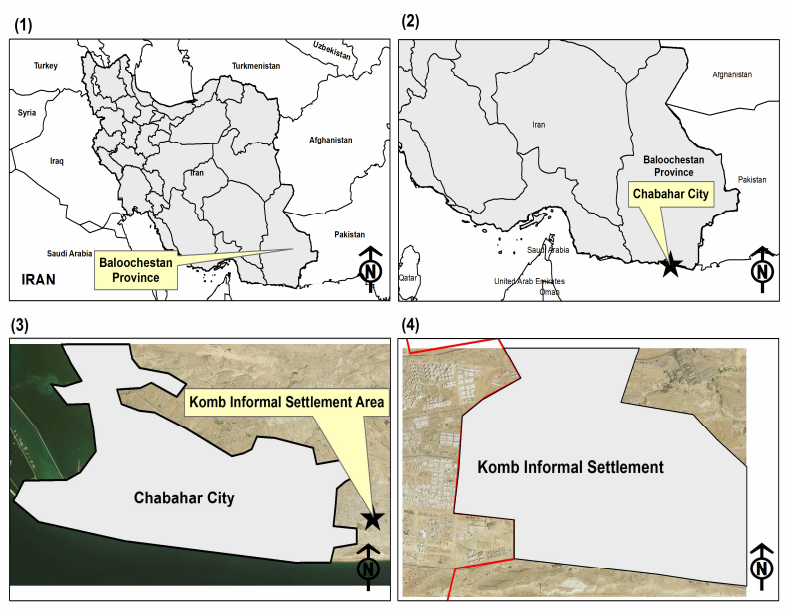

Fig. 2. Study area map.

According to the documents and satellite images, this settlement has been formed during a period of 20 years (since 1995 to 2017) particularly during 2000 - 2010 and has grown rapidly from 2010 to 2017. The area of Komb in 2017 was of about 421 hectares. The population of this settlement has increased from 41 people in 1986 to about 11,000 people in 2017 [38]. About 80\% of its constructions have been built in the period 2005 - 2017. About 92.6\% of its active population has been working in service sector, $4.4 \%$ in industry and $3 \%$ in agriculture. The household size was of 4.8 in 2010. The population has increased from 41 people in 1990 to 8,500 people in 2006 and to about 11,000 by the end of 2016. Around $54 \%$ of the population is aged 15 to 64 years, and more than $43 \%$ of the people older than 6 are illiterate; $30 \%$ of the people are unemployed even though at working age. Moreover, about $50 \%$ of the population of the settlement is represented by children and adolescents younger than 15 [39].

\subsection{Methods and data}

This research was conducted using documents and location data related to the settlement of Komb. The reason for choosing Komb settlement in this study is the unique position and the marginalization of this settlement from the main town and also its terrible spatial condition.

The major steps of the study are described as follows:

a). First, in January 2016, the author carried out a field observation and talked to some of local people, influential people, local authorities and councils of Komb in relation to the general situation of the neighbourhood so that the author could visualize the general framework.

b). The second step consisted in the collection of the general data on the demographic, economic, and cultural situation of the neighbourhood and the maps related to the land use, by referring to the Chabahar Municipality, the Housing Foundation of Islamic Revolution, the Health and Treatment Centre of Chabahar, and the Guide Plan Studies of Komb Settlement.

c). Thirdly, the spatial maps and data related to Komb settlement were extracted from the images of Google Satellite as well as the maps of Komb settlement guide plan and they were modified. Since the maps of the settlement were old, the author downloaded the most recent satellite images of the neighbourhood in 2017 by using the Ultimate Maps Downloader. Then, maps were digitalized and maps of blocking and passages network were prepared. Auto CAD Map and especially ARC GIS were used in this step for mapping and making the maps usable (GIS ready) (Fig. 3).

Then, field observations and neighbourhood visits were made from May to July, 2016 to record the situation of land use in the settlement. The maps of 
communication network, blocking, and spatial structure of the neighbourhood were extracted. One of the problems in this work phase was the lack of boundaries related to land pieces and it was tried, as much as possible, to re-block them.

d). In the fourth phase, the spatial structure of the neighbourhood was identified to provide the ground for suggestions about upgrading and connecting the settlement to the main city.

e). Lastly, the integrated spatial planning framework "ISPF" was used to connect the settlement to the main city. This approach includes four levels, namely city, neighbourhood, neighbourhood unit (blocks) and land pieces.

According to Abbott (2002a), the lack of appropriate data at the local level is common and therefore any data should be used to organize the settlements [13].

Thus, the author has tried to upgrade and complete location data as much as possible and provide the context to use integrated spatial planning framework.

\section{RESULTS AND DISCUSSION}

\subsection{Integration of informal settlements with the city}

Informal settlement of Komb has been formed since 1985 mainly through the establishment of inadequate housing and shacks around the city. Between 2000 and 2017, recording more than 90\% growth, it has spread sparsely and outside the main city. However, it was not until 2017 that the settlement was officially recognized by the civil managers and in informal plans of development such as the city master plan. The settlement is separated from the main city physically and in terms of management and no services are provided by the municipality to its dwellers (Fig. 4). However, the settlement is getting close to the main city through an arterial communication network. The formal city benefits from an urban development plan and the new settlements are formed by plans and receive services, but this informal settlement lacks in any urban development plans and no other specific urbanization plan has been developed to organize it.

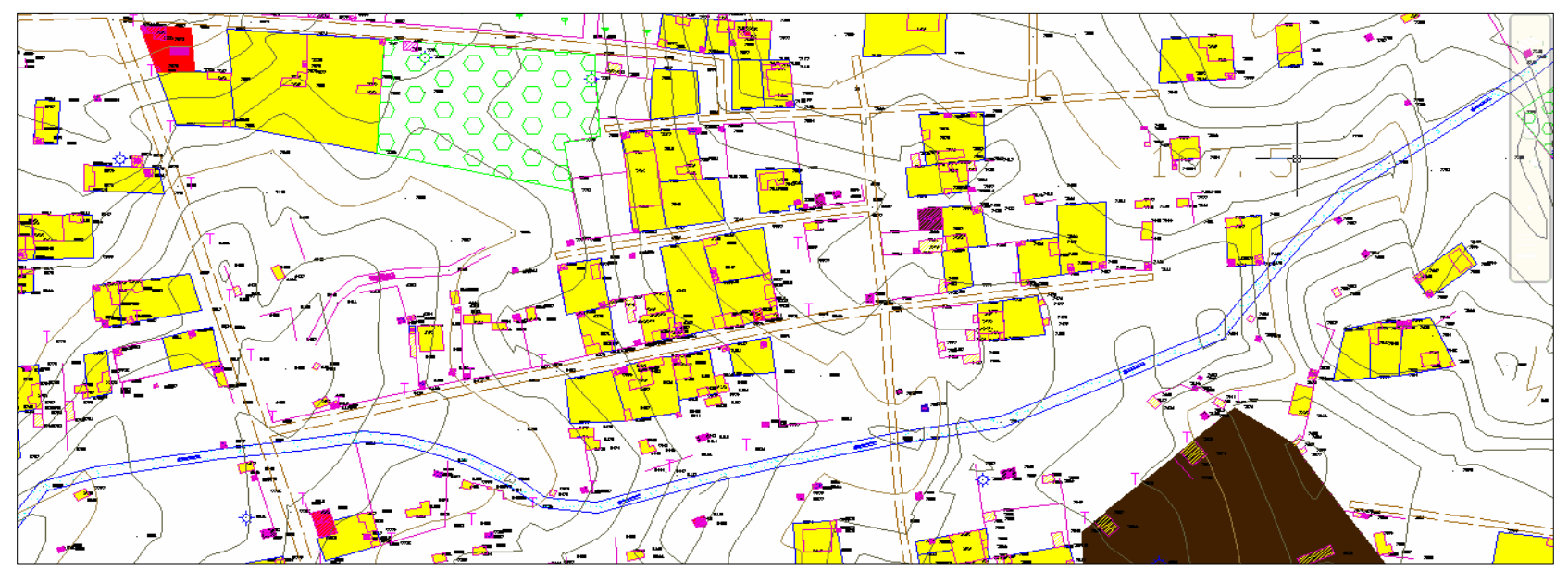

Fig. 3. Making the base maps for GIS ready format.

According to the integrated spatial planning approach, linking informal settlement to the main city is possible through developing and upgrading the communication network.

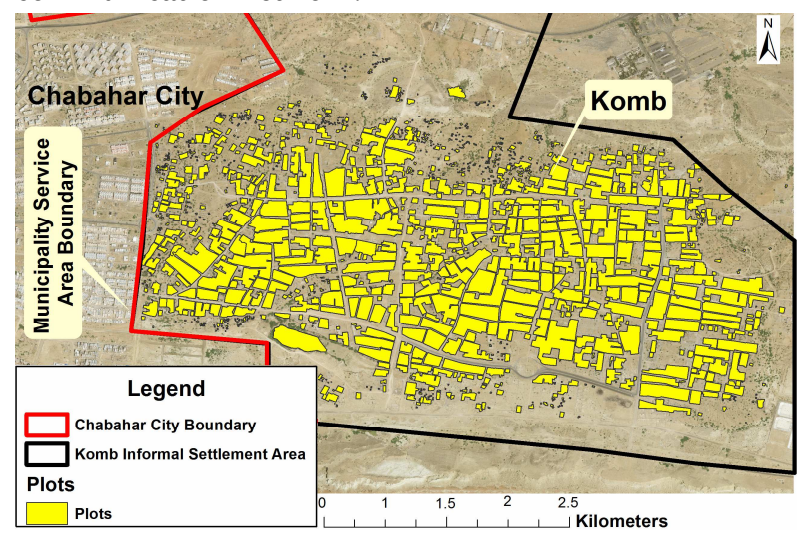

Fig. 4. Formal city versus informal settlement.
In order to make this connection, the available communication network should be upgraded and developed so that the settlement could be completely connected to the main city (Fig. 5).

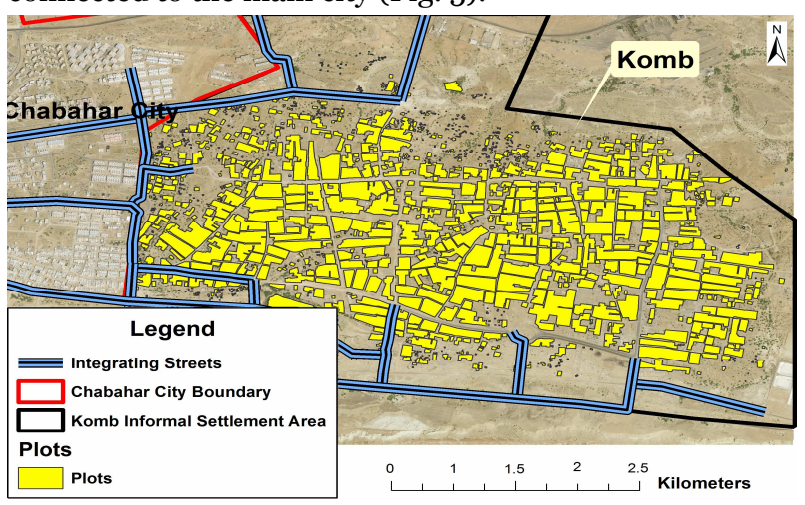

Fig. 5. Improving main streets to integrating settlement to the City. 


\subsection{Reforming spatial structure within the settlement}

Communication network within Komb settlement is a network of collecting and distributing streets and neighbourhoods that are formed organically and on south-north and east-west directions. The streets form joints, axes, and main skeleton of the neighbourhood (Fig. 6).

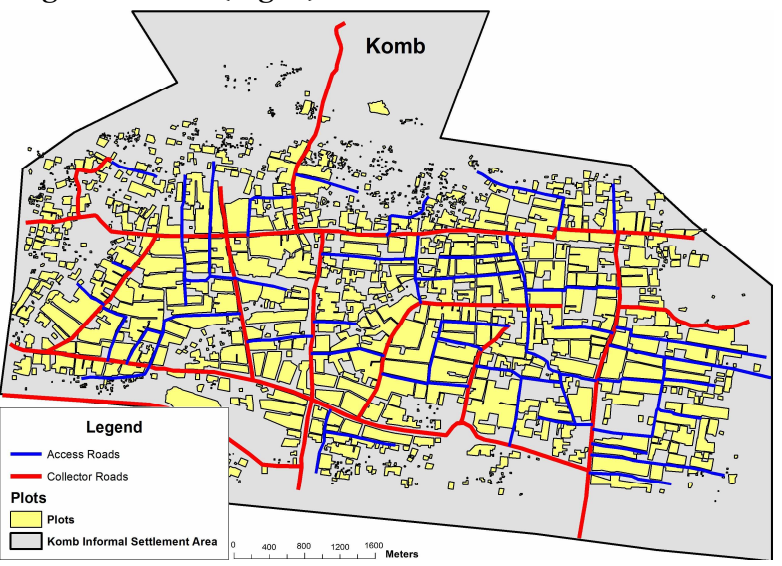

Fig. 6. Streets of the Komb settlement.

Due to the lack of regular roads, sewage systems and a good network to collect surface waters have not yet been formed and domestic wastewater often moves to the surface of passages. In order to solve these problems, it is possible to upgrade the streets network of the settlement while keeping the organic structure of the neighbourhood and access network of the settlement without major physical changes or destruction of building blocks. It is recommended to maintain the spatial structure of the neighbourhood and connect and link different parts of the neighbourhood by upgrading the pathways. This pattern includes 5 west-east streets and several northsouth streets, which should connect the neighbouring blocks and different parts of the neighbourhood to each other (Fig. 7).

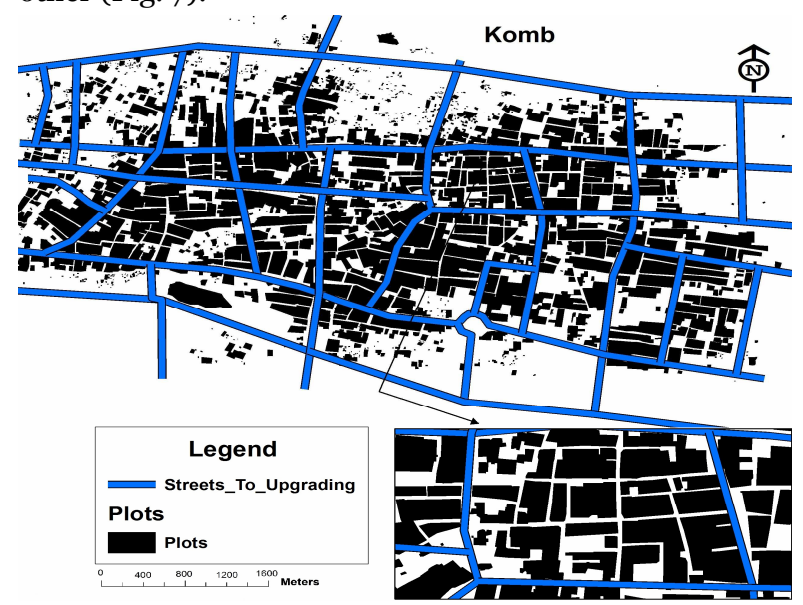

Fig. 7. Proposed streets for improvement.
Since making wide changes in the neighbourhood is not realistic, it is recommended to upgrade the pathways according to the available network of the neighbourhood.

The informal settlement of Komb lacks adequate public amenities and spaces such as parks, local business service centres, appropriate educational, health and treatment centres (Fig. 8), good network of roads, facilities related to waste collection and other services needed by residents.

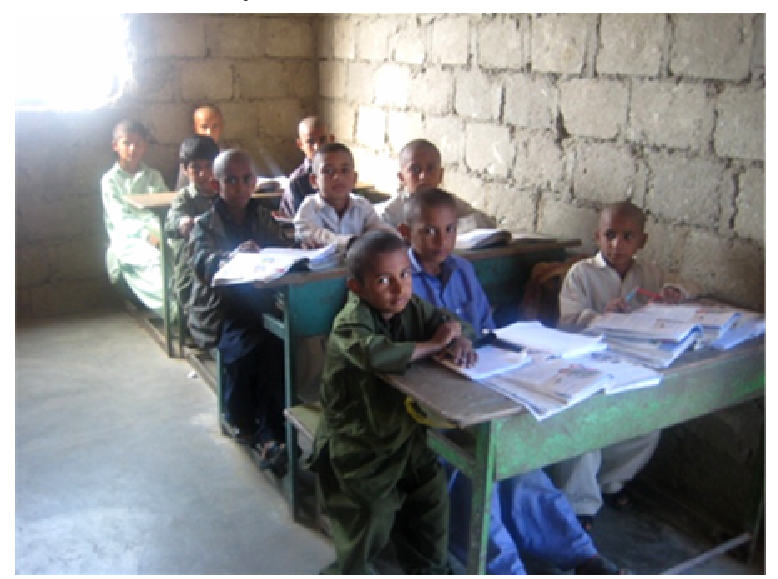

Fig. 8. Lack of appropriate training spaces.

According to the observations, the settlement lacked proper drinking water network, educational centres of junior high school (secondary school) and high school, and good quality treatment, administrative and police centres until the first half of 2017. Until then, only two primary schools were carrying out educational activities in rented buildings of residential use (Fig. 9).

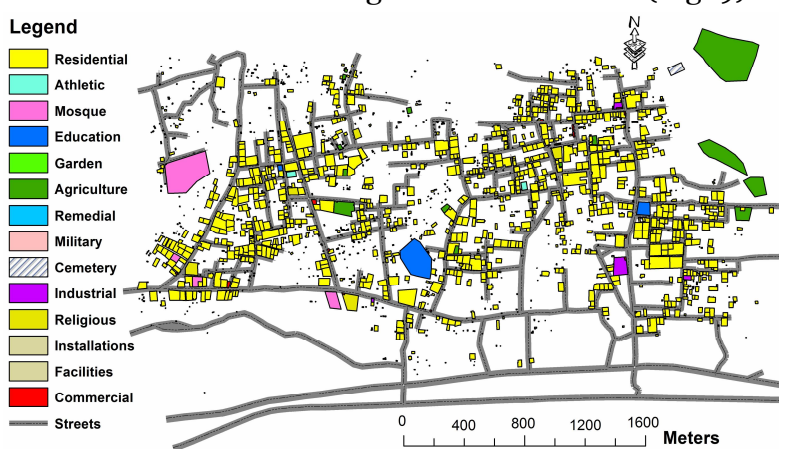

Fig. 9. Current land use map of Komb.

Due to the physical organic structure and lack of infrastructures, most of the wastewater accumulates on the surface of neighbourhoods as wetland and causes environmental pollution (Field Observations, 2016-1012) [38].

At this level, in addition to the suggestion of upgrading pathways by following and benchmarking the organic collector and distributor network, the settlement of Komb is divided into three smaller areas with a population of about 3,700 people in each neighbourhood. Due to scattered pieces of land, and 
the households' need to access services and facilities, and due to the collector and distributor streets, two community centres were proposed for each neighbourhood. The centres offer local and micro services in each neighbourhood within a distance of about 10 to 15 minutes walking (about 500 to 800 meters in any direction) (Fig. 10).

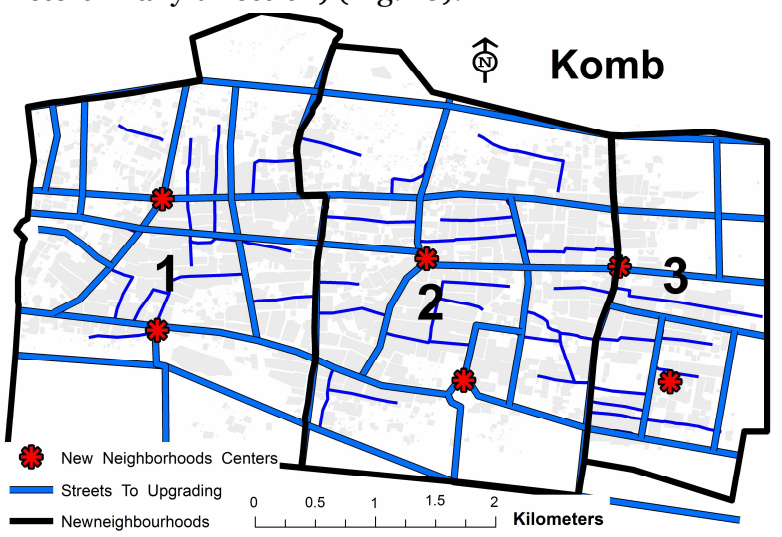

Fig. 10. New proposed neighbourhoods.

They also provide the ground for the formation of public places.

\subsection{Upgrading at the scale of neighbouring units}

The rapid growth of settlements, lack of previous plans and programs, poor spatial planning system, lack of active local institutions and illegal seizure of lands have led to organic and non-geometric blocking within the settlement. The settlement of Komb is made up of big blocks without any geometric arrangement while the neighbouring units are formed organically (Fig. 11).

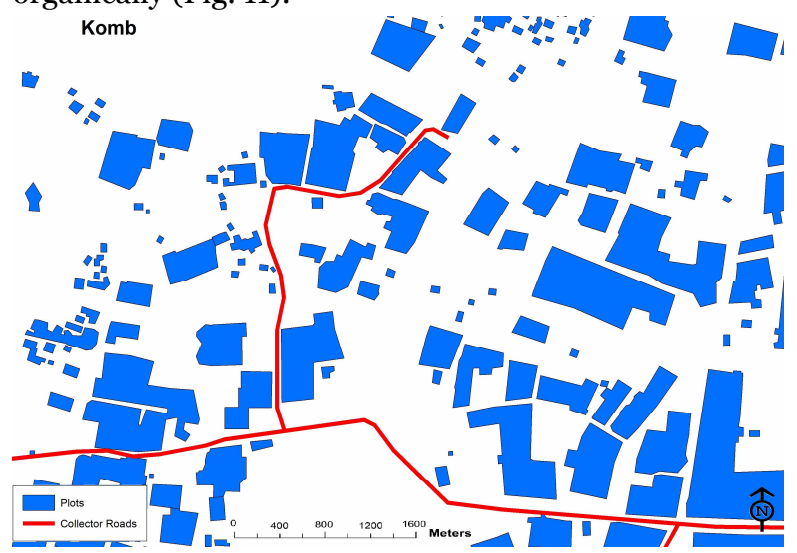

Fig. 11. Non-geometrically ordered property units.

During the formation of the settlement, dwellers bought land at very low prices from brokers and dealers or seized large pieces of land illegally. On average, each person occupied about $80 \mathrm{sq} \mathrm{m}$ of space. Therefore, seized lands have often been divided and separated as large areas, without geometric order. Field observations (Author survey, 2016-08-13) indicate that a significant portion of illegally constructed buildings have been and are still destroyed constantly by the local authorities and public bodies such as the governing institution. At this level, new neighbouring units were proposed. These units would provide services at the neighbouring unit scale. Organic pathways network, local community access, and physical access radius (of about 500 to 800 meters from each side) for the pedestrians were some of the main issues emphasized on in the definition of neighbouring units so that each person could get the required services from the neighbouring unit's centre by walking 5 to 10 minutes at most (Fig. 12).

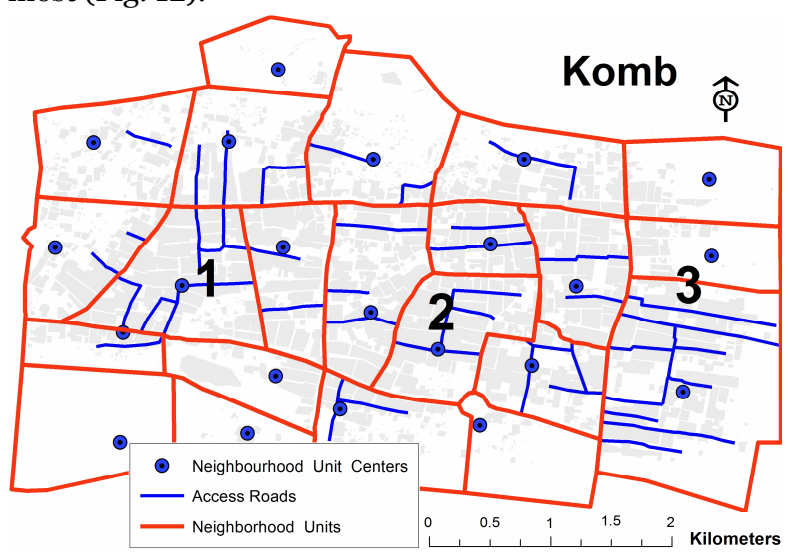

Fig. 12. New proposed neighbourhood units.

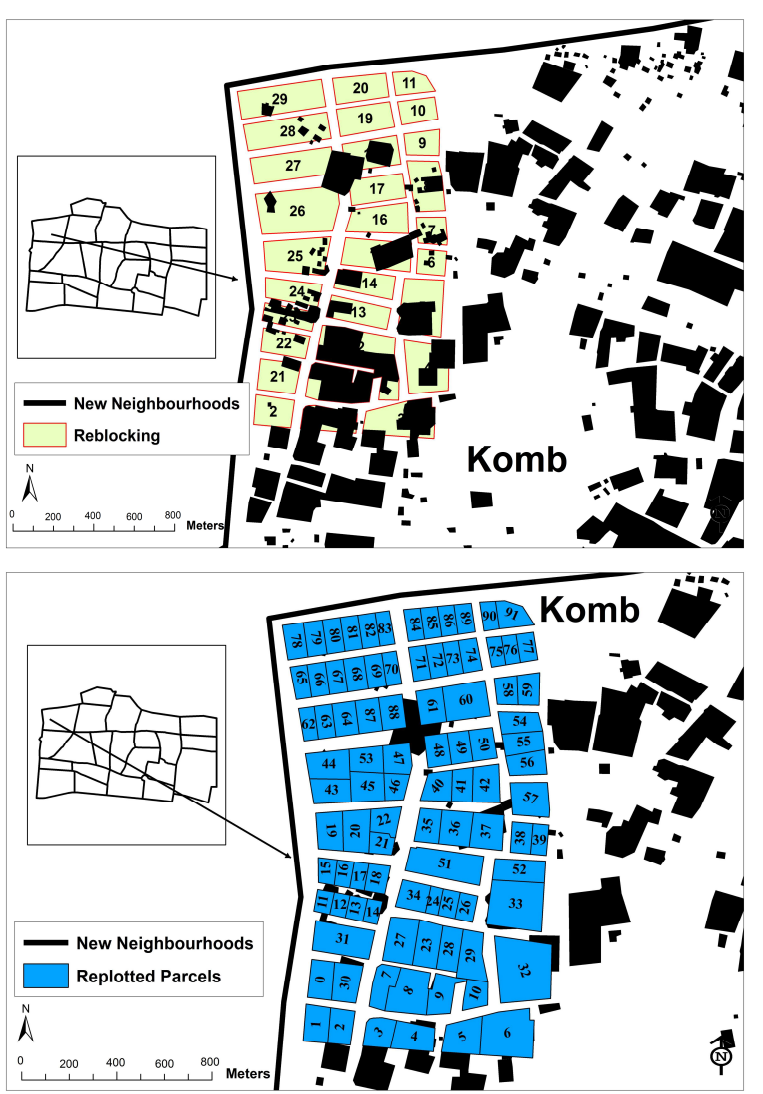

Fig. 13. Komb proposed parcels re-blocking and replotting. 
The use of land readjustment method including re-blocking and re-plotting (Fig. 13) is necessary for organizing land pieces at this level. Disputes over land ownership, opposition to the destruction of some new buildings, lack of funds and residents' participation can be the most important barriers at this level of planning. Therefore, re-blocking and re-plotting should be done with minimum damage to the body of the neighbourhood. Nevertheless, it is necessary to maintain the communication structure and keep and upgrade proper and useful buildings. Due to the weak economic foundation, undertaking measures for widespread physical changes would be unrealistic. Due to the shortage and lack of public service spaces at the level of neighbouring units, the vacant and interstitial lands can be used for making and developing such spaces. Re-blocking and re-plotting make it possible. In this study, for example, re-blocking and replotting have been suggested for neighbouring units and some services have been defined at the scale of neighbouring units (Fig. 14).

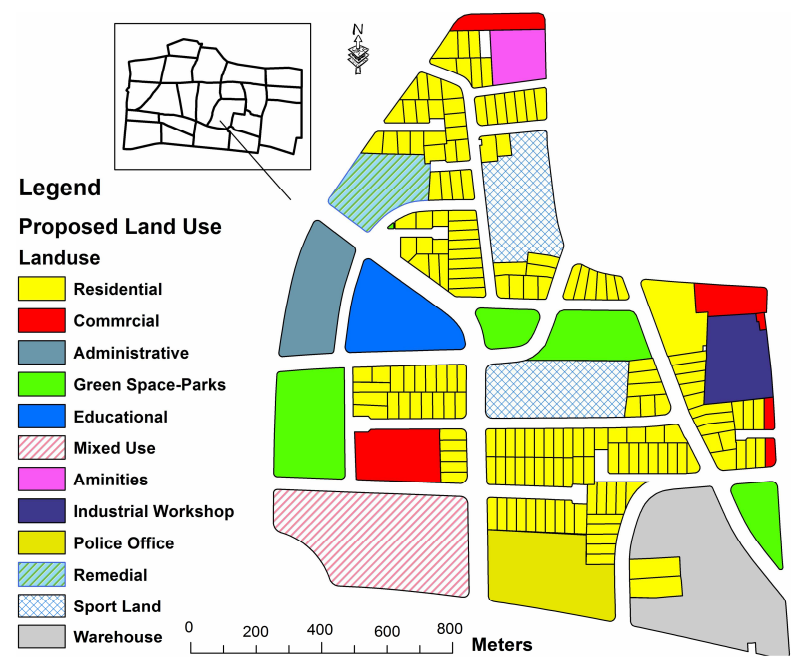

Fig. 14. Komb sample neighbourhood unit proposed land use.

\subsection{Upgrading at the scale of neighbour units}

Nearly $80 \%$ of the building blocks in the settlement of Komb have been built without an engineering plan and out of standard. Most of the houses have been built in the recent 15 years by means of concrete blocks materials, from wood and iron sheets (Fig. 15). Since most of the households earn less than 125 \& per month, this made them build non-standard and vulnerable houses [38]. According to the information obtained from Chabahar health centre (2016), due to the lack of a system to collect household waste, garbage depots that are formed in different parts of the neighbourhood cause the concentration of insects and animals and the occurrence of diseases such as malaria. Moreover, the lack of access to proper drinking water has led to the occurrence of kidney and gastrointestinal diseases in the settlement [39]. Therefore, at this scale, it is necessary to differentiate building blocks and identify needy households in the first phase. It is recommended to use household empowerment programs. Building blocks upgrading, micro finances to upgrade housing, local community participation, and hygienic and environmental programs at this level. Institutional capacity building and local community participation can be important at all levels of integrated spatial planning.

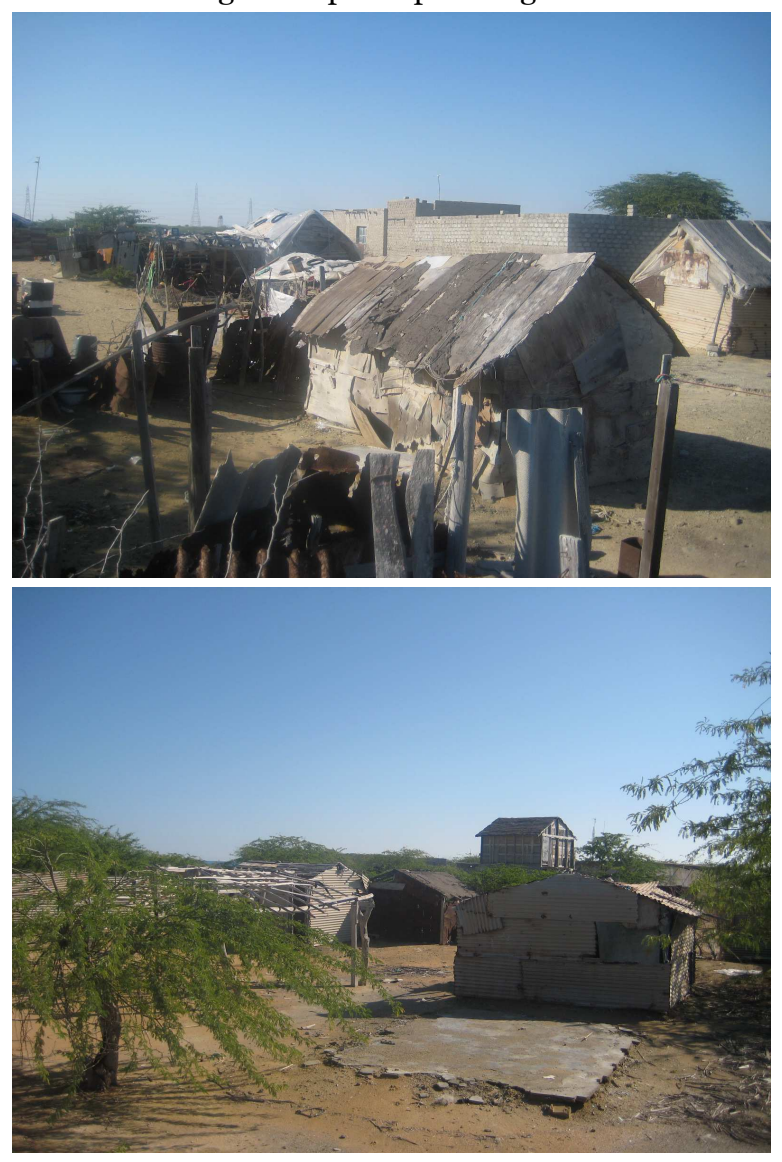

Fig. 15. Some houses of the Komb slum.

\section{CONCLUSION}

In this study we attempted to make suggestions to connect informal settlements to the main cities using integrated spatial planning approach. At the first level, it was proposed to link the settlement to the main city through upgrading passages network and offering services and infrastructures by the municipality. At the second level, upgrading interneighbourhood communication network and new neighbourhood were proposed to create the internal structure of the settlement and to connect neighbouring units one with each other. At this level, public service centres and places were proposed in new neighbourhoods. At the third level, it was suggested to 
divide neighbourhood to new neighbouring units, new centres were proposed at the scale of neighbouring units. To upgrade the settlement and to provide basic services, it was suggested to use re-blocking and replotting at this level. Furthermore, institutional capacity building was suggested in order to advance measures at the neighbourhood scale. At the fourth level, local community empowerment and implementation of social and economic programs were recommended. The empowerment includes a range of housing upgrading programs, teaching life skills, empowerment and improvement of environmental health and household health. In conclusion, implementing "integrated spatial planning" is quite practical and useful for upgrading the settlement of Komb and integrating (connecting and linking) it within the main city.

\section{REFERENCES}

[1] World Bank (2016), Development Goals in an Era on Demographic Change, http://www.worldbank.org/ en/publication/global-monitoring-report.

[2] UN-HABITAT (2014a), Housing \& Slum Upgrading, http://UnHABITAT.Org/Urban-Themes2/Housing-Slum-Upgrading/, Accessed 08.05.14.

[3] Statistic Centre of Iran 'SCI' (2014), Estimation of the population of Iran, http://www.amar.org.ir/ Default.aspx?tabid=650. Accessed 03.01.14. (In Persian).

[4] Urban Development and Renovation Organization "UDRO” (2016), About 20 million live in Iran's urban slums. URL hamshahrionline.ir/ details/258880. Accessed February 2017, (In Persian).

[5] Irandoost, K. (2009), Informal Settlements and the Myth of Marginality, Tehran: Tehran Municipality Publication, 2009, (In Persian).

[6] Abbott, J. (2002b), A Method-Based Planning Framework for Informal Settlement upgrading, HABITAT International, 26 (3) pp. 317-333.

[7] Amis, P. (2001), Rethinking UK aid in urban India: Reflections on an impact assessment study of slum improvement projects, Environment and Urbanization, 13(1), pp. 101-114.

[8] Abbott, J. (2000a), An Integrated Spatial Information Framework for Informal Settlement Upgrading, International Archives of Photogrammetry and Remote Sensing, Vol. XXXIII, Part B2.

[9] Abbott, J. (200ob), Cape Town: seeking social sustainability in a fast-growing city. In M. Polese, \& R. Stren (Eds.). The social sustainability of cities: diversity and the management of change, pp. 280-307, Toronto: Toronto Press.

[10] Urban Development and Revitalization Organization “UDRO” (2009), Report of Chabahar city slums identification plan, archived hardcopy, (In Persian).
[11] UN- HABITAT (2011), Streets as Pillars of Urban Transformation: A UN-HABITAT Approach to Participatory Street-Led Citywide Slum Upgrading, 2011, Nairobi.

[12] Huchzermeyer, M. (2006), The struggle for in situ upgrading of informal settlements: Case studies from Gauteng, Paper to be presented at the Southern African Housing Foundation Conference \& Exhibition, Cape Sun, 9-11 October 2006, pp. 235-242.

[13] Abbott, J. (2002a), An analysis of informal settlement upgrading and critique of existing methodological approaches, HABITAT International, 26 (3) pp. 303-315.

[14] Pugh, C. (1995), The role of the World Bank in housing, In B. Aldrich, \& R. Sandhu (Eds.), Housing the urban poor: Policy and practice in developing countries. London: Zed Books, 1995.

[15] Choguill, C. L. (1999), Community infrastructure for low-income cities: The potential for progressive improvement, Habitat International, 23 (2), pp. 298-301.

[16] World Bank (1991), Urban Policy and Economic Development: An Agenda for the 1990s, Http://Dx.Doi.Org/10.1596/o-8213-1816-o.

[17] Huchzermeyer, M. (1999), The exploration of appropriate informal settlement intervention in South Africa: Contributions from a comparison with Brazil, Ph.D. thesis, South Africa: University of Cape Town.

[18] Ferguson, B., Navarrete, J. (2003), A financial framework for reducing slums: Lessons from experience in Latin America. Environment and Urbanization, 15(2):201-215. DOI: 10.1630/095624 703101286646.

[19] Cities Alliance (1999), Cities without Slums, 1999, From: www. Cities alliance. Org. Accessed 27 February 2017.

[20] Satterthwaite, D. (2012), Upgrading informal Settlements, In book: International Encyclopaedia of Housing and Home, 2012, pp. 206-211. DOI: 10.1016/B978-0-08-047163-1.00276-9.

[21] UN-HABITAT (2014c), A Practical Guide to Designing, Planning, and Executing Citywide Slum Upgrading Programs, From: http://unHABITAT.org /books/a-practical-guide-to-designing-planning-andexecuting-citywide-slum-upgrading-programmes/. Accessed on 24 December 2016.

[22] Choguill, C. L., Franceys, R., Cotton, C. (1993), Building community infrastructure in the 1990s. Progressive improvement, HABITAT International, 17(4), pp. 2-3.

[23] Choguill, C. L., Franceys, R., Cotton, C. (1994), Building community infrastructure in the 1990s, Overcoming constraints, HABITAT International, 18(1), p. 4.

[24] Hamdi, N., Goethert, R. (1996), Action planning for cities, a guide to community practice, Chichester, New York: Wiley. 
[25] Jiminez, D. V. (1992), Landslides in the squatter settlements of Caracas; Towards a better understanding of causative factors, Environment and Urbanisation, (2), pp. 80-89.

[26] Fadare, W., Mills-Tettey, R. (1992), Squatter settlement in Port Harcourt, Habitat International, 16(1), pp. 71-81.

[27] Lee-Smith, D. (1989), Squatter landlords in Nairobi: a case study of Korogocho, In P. Amis, \& P. Lloyd (Eds.), Housing Africa's urban poor. Manchester: Manchester University Press.

[28] Reichenheim, M., Harpham, T. (19991), Maternal mental health in a squatter settlement, Rio de Janeiro, British Journal of Psychiatry, 159, pp. 683690.

[29] Hardoy, J. E., Mitlin, D., Satterthwaite, D. (2013), Environmental Problems in an Urbanizing World: Finding Solutions in Cities in Africa. Earthscan Publications.

[30] Friedman, M. (2001), Gender and poverty study for the new rest informal settlement Cape Town, a document prepared for the Cape Metropolitan Council. Cape Town.

[31] Moser, C. (1995a), Confronting crisis: A comparative study of household responses to poverty and vulnerability in four poor urban communities, Environmentally Sustainable Development Studies and Monographs Series No. 8. Washington, DC: The World Bank.

[32] UNCHS (1996), Urban poverty: A world challenge-the Recife declaration, March 1996, Habitat II, Recife International Meeting on Urban Poverty, Recife, Brazil, 17-21 March.
[33] Moser, C. (1995b), Urban social policy and poverty reduction, Environment and Urbanisation, 7(1), pp. 159-171.

[34] UN-HABITAT (2014b), Streets as Tools for Urban Transformation in Slums: A Street-Led Approach to Citywide Slum Upgrading Participatory. UN Habitat Publications.

[35] Karbben, V. D. E., Needham, B. (2008), Land readjustment for value capturing. A new planning tool for urban redevelopment, TPR, 2008, 79 (6), pp. 651672.

[36] Abbott, J., Martinez, I., Huchzermeyer, M. (2001), An analysis of informal settlements and applicability of visual settlement planning (ViSP) in South Water Research Commission Report No. 786/1/01, Pretoria.

[37] Imperato, Ruster, J. (2000), Participatory urban upgrading: A road map for going to scale. Presented to the Fifth Global Forum of the Water Supply and Sanitation Collaborative Council, Foz do Igua-cu, Brazil, 24-29 November 2000.

[38] Chabahar County Housing Foundation of Islamic Revolution "CCHFIR" (2016), Komb Guidance Plan Report, Archived hardcopy document, archived not published hardcopy, (In Persian).

[39] Health Centre of Chabahar County "HCCC" (2016), Statistics of Chabahar County, archived not published hardcopy, 2016, (In Persian). 